\title{
Kawasaki disease and hepatobiliary involvement: report of two cases
}

\author{
Ingeborg Marianne Keeling ${ }^{*}$ (D), Elisabeth Beran and Otto Eugen Dapunt
}

\begin{abstract} together with KD has not been described earlier. neuropathy. The coronary artery system was not involved in either case. coronary artery aneurysm and stenosis.

\section{Background}

Various manifestations of Kawasaki disease (KD) occur at an early age. When the hepatobiliary tract is primarily affected, the diagnosis relies mainly on symptoms, ultrasonography and laboratory parameters of systemic vasculitis. Numerous diseases must be excluded. Incomplete and atypical cases are difficult to detect. Rapid diagnosis and treatment are crucial, as $4 \%$ of KD patients develop coronary artery $(\mathrm{CA})$ involvement $[1]$.
\end{abstract}

Background: Kawasaki disease (KD) without affection of the coronary artery system is rare. Optic nerve pathology

Case presentation: We present one case of KD in a 12-year-old girl predominantly with prolonged cholestasis, and a second case of multiple recurrent KD in a 9-year-old boy with hepatomegaly and ischemic optic nerve

Conclusions: KD warrants rapid diagnosis and immediate specific treatment in order to prevent the high risk of

Keywords: Kawasaki disease, Hepatopathy, Cholestasis, Ischemic optic nerve neuropathy, Differential diagnosis

\section{Case presentation}

\section{Case 1}

A 12-year-old girl presented with a 6-day history of subfebrile temperature, generalized lymphadenitis, fatigue and inappetence. Exanthema of the extremities and trunk, raspberry tongue, bulbar injection, facial edema, palmar erythema, swelling of the small-finger joints, discrete jaundice and epigastric tenderness were observed. The general practitioner (GP) had treated her (benzathin-phenoxymethyl penicillin, $750 \mathrm{mg}$ TID) for suspected scarlet fever.

Laboratory data (and normal range in parenthesis) were:

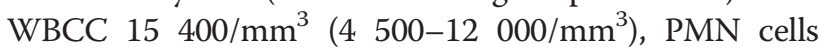
$73.4 \%$ (50.0-75.0 \%), lymphocytes $9.4 \%$ (20.0-40.0 \%), eosinophils $9.0 \%(0-5.0 \%)$, platelets $451000 / \mathrm{mm}^{3}(140$ 000-440 000/ $\left.\mathrm{mm}^{3}\right)$, CRP $15 \mathrm{mg} / \mathrm{l}(0-8 \mathrm{mg} / \mathrm{l})$, ASL 971U/

\footnotetext{
* Correspondence: ingeborg.keeling@medunigraz.at

Department Cardiac Surgery, Medical University of Graz, Auenbruggerplatz 29, 8036 Graz, Austria
}

$\mathrm{dl})$, esterized bilirubin $2.86 \mathrm{mg} / \mathrm{dl}(<0.20 \mathrm{mg} / \mathrm{dl})$, ASAT 17U/l (0-21U/l), ALAT 42U/l (0-22U/l), GGT 50U/1 (019U/l), AP 557U/l (0-390U/l), HDL cholesterol $5 \mathrm{mg} / \mathrm{dl}$ $(\geq 37 \mathrm{mg} / \mathrm{dl})$, bilirubinuria, and ketonuria. Hepatitis screening revealed borderline complement binding reaction for Enterovirus and Coxsackievirus types other than A9. The chest $x$-ray showed prominent hila and the ECG a normofrequent sinus rhythm. Echocardiography indicated normal left ventricular function. CAs had normal dimension, no signs of aneurysm. Liver ultrasonography revealed distinct periportal fields. Clinical symptoms suggested KD with uncommon cholestasis. On the day of admission, treatment was started with intravenous immune globulin (IVIG) (Octagam, $1.6 \mathrm{~g} / \mathrm{kg} / \mathrm{d})$, aspirin (ASA, $500 \mathrm{mg}$ TID), sucralfate (1 g TID), and ursodeoxycholic acid (100 mg TID).

Desquamation of the fingertips and pronounced jaundice developed. The blunt liver margin was palpated $0.5-1 \mathrm{~cm}$ underneath the right costal edge and hepatic consistency was found normal. Moderately acholic stools and hyperchromic urines were noted. Ultrasonography and MRI showed hepatomegaly $(13 \times 16 \times 9.6 \mathrm{~cm})$ and reguar width of intra- and extrahepatic bile ducts. After 10 days, the patient improved and was discharged with Immunologic screening revealed positive anti-Ro-antibodies and a positive anti- $\mathrm{U}_{1}$-snRNP subset (against extractable 
nuclear antigen-ribonucleoprotein). Four months after discharge, transaminases and platelet counts normalized while total cholesterol $(249 \mathrm{mg} / \mathrm{dl}$, normal $<200 \mathrm{mg} / \mathrm{dl})$ and eosinophils (11.1\%, normal 0-5.0 \%) remained elevated.

\section{Case 2}

Since his fourth month of life, a 9-year-old boy experienced upper respiratory infections and recurrent otitis.

At the age of 4 years he was admitted 5 days after headaches, conjunctival injection, fever, fatigue, enanthema of the throat and tonsils, raspberry tongue and enlargement of submandibular lymph nodes evolved. Laboratory results were: WBCC $27300 / \mathrm{mm}^{3}$, (4 500-12 000/ $\left.\mathrm{mm}^{3}\right)$, platelets $594999 / \mathrm{mmm}^{3}\left(140000-440000 / \mathrm{mm}^{3}\right)$, CRP $25 \mathrm{mg} / \mathrm{l}(0-8 \mathrm{mg} / \mathrm{l})$, ESR 60/96 (3-13 mm/1 h), ASL and RF negative. Although an exanthema was missing, clinical findings suggested incomplete KD. Treatment consisted of IVIG (Octagam $^{\circ}, 2 \mathrm{~g} / \mathrm{kg} / \mathrm{d}$ ), and high-dose ASA (300 mg QID) for 3 weeks. Fever resolved within $24 \mathrm{~h}$. Desquamation of the toes developed upon discharge.

After persistent fever for 10 days at age 6 years, resistant to antibiotic treatment occurred along with repeated vomiting, fatigue, angina, headaches, photophobia, raspberry tongue and desquamation of the toes. Laboratory data were: WBCC $21800 / \mathrm{mm}^{3}$, platelets $746000 / \mathrm{mm}^{3}$, CRP $22 \mathrm{mg} / \mathrm{l}$, ESR $110 \mathrm{~mm} / 1 \mathrm{~h}$. Recurrent incomplete KD was diagnosed. The child developed intolerance to IVIG (Endobulin ${ }^{\circ}, 5 \mathrm{~g}$ ), with severe abdominal pains. The liver margin was palpable $0.5 \mathrm{~cm}$ below the right costal edge, hepatic consistency was normal. Stool and urine were unremarkable. Only once during the hospital stay ASAT 26U/l (0-21U/l) and ALAT 23U/l (0-22U/l) were slightly elevated. CT showed hepatomegaly, a prominent, homogenous pancreas, and reflections, possibly small sedimentations, in the choledochus duct. The examination neither confirmed nor dismissed an autoimmune disease. Reduced tissue necrosis factor (TNF)-receptor levels $(0.81 \mathrm{ng} / \mathrm{ml} ; 50 \%$ of the minimum norm) suggested autosomal-dominant TNF-receptor associated periodic fever syndrome (TRAPS), but exon 2-5 mutations of the TNFR1A1 gene were not found in PCR.

At the age of 9 years the patient was admitted for acute right-sided ablepsia. The ophthalmologist diagnosed ischemic optic nerve neuropathy. High-dose steroids for 13 days incompletely restored the child's vision. The examination for an autoimmunologic disease was negative.

\section{Conclusions}

In both exposed cases, KD was strongly suggested at admission. Uncommon clinical features in these two children were hepatopathy, cholestasis and diarrhea. In case 1, hepatomegaly and cholestasis, with distinct periportal fields, were identified by ultrasonography and MRI. In case 2 , hepatomegaly with cholangitis was present. The CA system was unaffected. The predominant gastrointestinal manifestation in up to $13.9 \%$ of KD cases is acalculous gallbladder hydrops, which may require cholecystectomy or percutaneous transhepatic biliary drainage [2]. Hepatopathy exceptionally rarely induces hepatocellular necrosis [3]. Other manifestations include hepatitis, pancreatitis, enteritis and ileus. Gilbert's syndrome with concurrent infection may resemble KD in clinical terms.

Childhood diseases like scarlet fever may manifest symptoms of hepatopathy and cholestasis. Coxsackievirus and Enterovirus associated hepatopathy were unlikely, as cholestasis without hepatitis, and elevated ESR and PMN are usually unrelated to these viral infections. In any case, KD-related macrophage activation syndrome (MAS) should be also suspected if liver dysfunction presents with other typical abnormal laboratory findings, such as cytopenia, hyperferritinemia and elevated serum LDH.

Initial antibiotic treatment for suspected bacterial infection, as in the present case, renders drug sideeffects an important differential diagnosis. In case 1, where positive Ro-antibodies, extractable nuclear antigenribonucleoprotein $\left(\mathrm{U}_{1}\right.$-snRNP), and elevated eosinophils suggested autoimmune hepatopathy rather than penicillin reaction, jaundice subsided without treatment 5 weeks post-discharge.

Toxic shock syndrome (TSS) may mimic KD. A connection between staphylococcal and streptococcal TTS and KD has also been suggested [1].

Specific immunologic alterations may be found in KD, which requires extensive immunologic testing and the use of image processing to confirm KD diagnosis. Therefore, in complex KD cases multispecialist approach, including the pediatric cardiologist, immunologists, rheumatologist, hepatologist, infectiologist, ophthalmologist, intensive care personnel, and clinical pharmacologist, are essential to avoid the many pitfalls of rapid diagnosis.

KD patients with fever, CRP $>10 \mathrm{mg} / \mathrm{dl}$, LDH $>590 \mathrm{U} / \mathrm{l}$ and/or hemoglobin $<10 \mathrm{~g} / \mathrm{dl}$, and those with high bilirubin and transaminases, are considered non-responsive to IVIG [4]. IVIG resistance with persistent or recrudescent fever occurs in approximately $18 \%$ of KD patients. Retreatment involved more individual adjustment, consisting of intravenous steroid pulse therapy, infliximab, cyclophosphamide, anakinra, etanercept, methotrexate, or plasmapheresis [1, 4-6]. Additionally, antioxidants, as vitamin $\mathrm{C}$, and drugs affecting cholesterol levels, can reduce endothelial dysfunction.

Abnormalities of liver function tests are frequently found in patients with acute KD. Indeed, children with abnormal liver function tests are at higher risk for IVIG resistance $[7,8]$. Moreover, ultrasonographic biliary findings or higher AST levels may be risk factors for coronary artery abnormality as a complication and/or recurrent $\mathrm{KD}$ if they are present during the first episode $[9,10]$. 
After repeated KD episodes, case 2 developed an extremely rare ophthalmologic KD manifestation, specifically ischemic optic nerve neuropathy, which to our knowledge is the first reported case of optic nerve pathology associated with KD [11]. However, transient affliction of the cranial nerves may at times be either the presenting feature or a complication of an otherwise uncomplicated KD in infants and children. Oculomotor nerve palsy may resolve after IVIG therapy [12].

In conclusion, atypical KD calls for extreme alertness, rapid diagnosis and immediate treatment if suggested. The absence of CA lesions and the presence of cholestasis may delay the diagnosis and specific treatment of this potentially life-threatening disease with severe long-term consequences.

\section{Consent}

Written informed consent was obtained from the parents of the patient for publication of this case report. A copy of the written consent is available for review by the Editor-in-Chief of this journal.

\section{Abbreviations}

GP: general practitioner; TID: three times per day; QID: four times per day; ASL titer: antistreptolysine titer; WBCC: white blood cell count; PMN: polymorphonuclear; CRP: C-reactive protein; ESR: blood sedimentation rate; ATIII: antithrombin III; ASAT: aspartate amino transferase; ALAT: alanine amino transferase; GGT: Y-glutamyl transferase; AP: alkaline phosphatase; HDL: high-density lipoprotein; RBCC: red blood cell count; MRI: magnetic resonance imaging.

\section{Competing interests}

The authors declare that they have no competing interests.

\section{Authors' contributions}

IMK wrote the manuscript, EB and OED contributed valuable discussion.

All authors read and approved the final manuscript.

Received: 8 November 2015 Accepted: 29 February 2016

Published online: 08 March 2016

\section{References}

1. Sánchez-Manubens J, Bou R, Anton J. Diagnosis and classification of Kawasaki disease. J Autoimmun. 2014;48-49:113-7.

2. Zulian F, Falcini F, Zancan L, Martini G, Secchieri S, Luzzatto C, et al. Acute surgical abdomen as presenting manifestation of Kawasaki disease. J Pediatr. 2003;142:731-5

3. Majumdar I, Wagner S. Kawasaki disease masquerading as hepatitis: a diagnostic challenge for pediatricians. Clin Pediatr. 2016;55:73-5.

4. Newburger JW, Takahashi M, Gerber MA, Gewitz MH, Tani LY, Burns JC, et al Diagnosis, treatment, and long-term management of Kawasaki disease: a statement for health professionals from the Committee on Rheumatic Fever, Endocarditis, and Kawasaki Disease, Council on Cardiovascular Disease in The Young, American Heart Association. Pediatr. 2004;114:1708-33. Erratum in: Pediatr 2005:115:1118.

5. Hashkes PJ, Becker ML, Cabral DA, Laxer RM, Paller AS, Rabinovich CE, et al. Methotrexate: new uses for an old drug. J Pediatr. 2014;164:231-6.

6. Lee WC, Hwang KP, King YT, Chen HC, Chiou SS, Yang RC, et al. Late diagnosis of Kawasaki disease is associated with haptoglobin phenotype. Eur J Clin Invest. 2000;30:379-82.

7. Eladawy M, Dominguez SR, Anderson MS, Glodé MP. Abnormal liver panel in acute kawasaki disease. Pediatr Infect Dis J. 2011:30:141-4.

8. Liu L, Yin W, Wang R, Sun D, He X, Ding Y. The prognostic role of abnormal liver function in IVIG unresponsiveness in Kawasaki disease: a meta-analysis. Inflamm Res 2015 Dec 8 [Epub ahead of print].
9. Yi DY, Kim JY, Choi EY, Choi JY, Yang HR. Hepatobiliary risk factors for clinical outcome of Kawasaki disease in children. BMC Pediatr. 2014;14:51. doi:10.1186/1471-2431-14-51.

10. Yang HM, Du ZD, Fu PP. Clinical features of recurrent Kawasaki disease and its risk factors. Eur J Pediatr. 2013;172:1641-7.

11. Anand S, Yang YC. Optic disc changes in Kawasaki disease. J Pediatr Ophthalmol Strabismus. 2004;41:177-9.

12. Thapa R, Mallick D, Biswas B, Chakrabartty S. Transient unilateral oculomotor palsy and severe headache in childhood Kawasaki disease. Rheumatol Int. 2011;31:97-9.
Submit your next manuscript to BioMed Central and we will help you at every step:

- We accept pre-submission inquiries

- Our selector tool helps you to find the most relevant journal

- We provide round the clock customer support

- Convenient online submission

- Thorough peer review

- Inclusion in PubMed and all major indexing services

- Maximum visibility for your research

Submit your manuscript at www.biomedcentral.com/submit 